\title{
Influence of the common mode impedance paths on the design of the EMI filters used with SiC-buck converter
}

\author{
Jean-luc Kotny ${ }^{1}$, Thierry Duquesne ${ }^{1,2}$, Nadir Idir ${ }^{1,2}$ \\ ${ }^{1}$ University of Lille $1,{ }^{2}$ L2EP Laboratory \\ Bat. P2, Cité scientifique, Villeneuve d'Ascq, France \\ *corresponding author, E-mail: jean-luc.kotny@univ-lille1.fr
}

\begin{abstract}
This paper deals the design method of EMI filter associated with buck converter using silicon carbide $(\mathrm{SiC})$ power semi-conductors. It's well known that to comply with EMC standards, EMI filters are necessary. The aim is to propose a design method based on an equivalent electrical circuit. Thus, the first step is the identification of the different elements of the proposed model but also the limits values of the parasitic elements of the passive components which play a major influence on the efficiency of the filters. The main objective is to study the influence of the common mode paths on the design of the filter before and after its installation. A filtering solution is proposed to reduce the high frequency disturbances caused by the fast $\mathrm{SiC}$ components. The simulation results obtained with the proposed model are compared with the measurements show the effectiveness of the proposed EMI filter design method.
\end{abstract}

\section{Introduction}

The utilization of the fast power switches based on the $\mathrm{SiC}$ or $\mathrm{GaN}$ semi-conductor materials will result in higher operating frequencies of static converters, this has as consequence the increases of the conducted emissions toward the power network [1-7]. The main solution used to reduce these conducted emissions consists to use passive filters made from the inductors and capacitors [8-10]. The properties of magnetic materials used in the inductors have a great influence on the performances of the filter [11]-[12]. Many studies have highlighted couplings between the passive components and the tracks, which can reduce its effectiveness. These parasitic couplings are mainly linked to the geometrical characteristics of the printed circuit board (PCB) and the properties of the magnetic cores. To optimize the size and performances of the EMI filters, the use of simulation can be a solution to reduce the cost and design duration. However, the simulation requires a more accuracy models of EMI filter components. Different high frequency models including the parasitic elements are proposed in literature [10-12]. In this paper, a high frequency model of the EMI filter which takes into account the common mode paths impedance is proposed. It's used to study the influence of this impedance on the efficiency of the filter during the design process.

\section{EMI Filter design}

In this study, the experimental setup used a SiC-buck converter supplied through a LISN by $\mathrm{E}=200 \mathrm{~V}$ and loaded by $\mathrm{R}=60 \Omega$ and $\mathrm{L}=0.73 \mathrm{mH}$. The operating frequency is fixed at $\mathrm{f}_{\mathrm{SW}}=200 \mathrm{kHz}$. The experimental setup used in this study is shown in figure 1. The LISN and the spectrum analyzer are placed directly on the ground plane. The Buck converter and its filter are placed on wooden blocks at $10 \mathrm{~cm}$ of the ground plane. It is the same for the R-L load and its 2 wires shielded cable. It is connected on one side to the converter metallic box and the other to the load box. The LISN is connected to a DC power supply by two wires unshielded cable (two wires for power supply and third one connected to the ground). The ground of the LISN is connected directly to the ground plane by a copper wire as shown in figure 2.

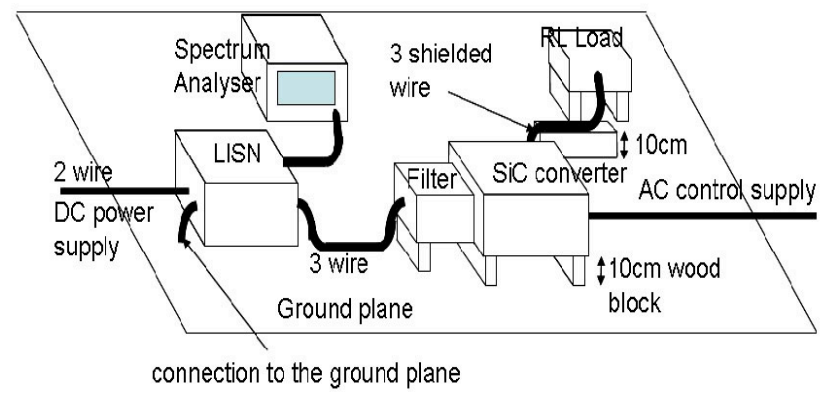

Figure 1: Experimental setup.

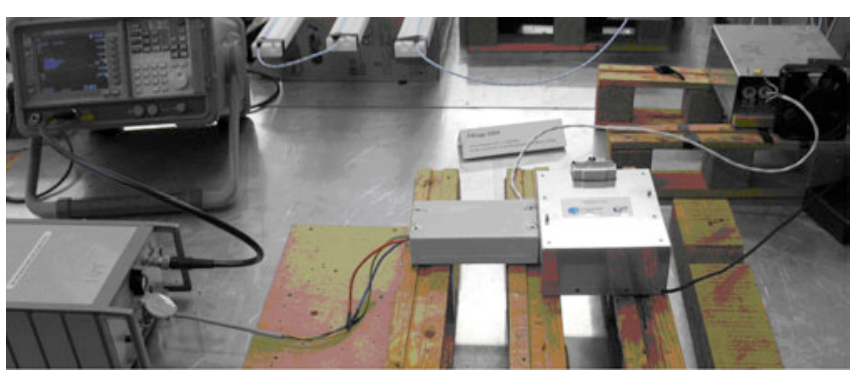

Figure 2: Photo of experimental setup.

The figure 3 shows the inner view of the $\mathrm{SiC}$ converter used in this study. 


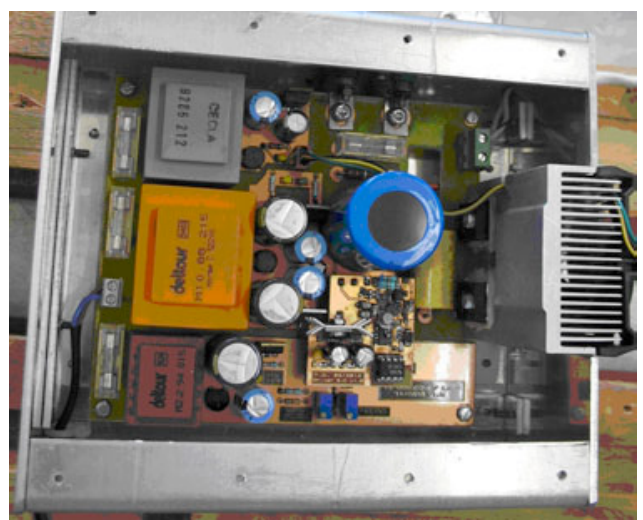

Figure 3: SiC-Buck converter.

The common mode (CM) and differential mode (DM) currents are measured using current probes on the supply wires between the LISN and the converter as shown in figure 4.

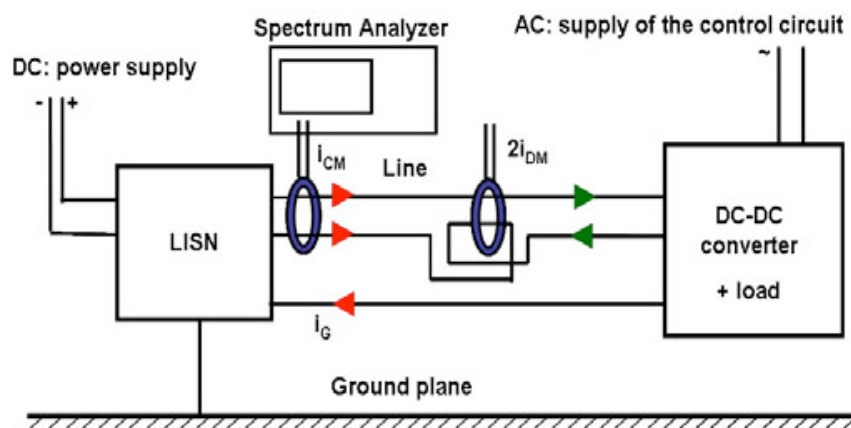

Figure 4: Method using current probes.

The measured CM and DM currents are shown in figure 5. The determination of attenuation required is obtained making the difference between the measured currents and the limit given by the EMC standards. Thus, attenuation requirements for the two modes are shown in figure 6 .

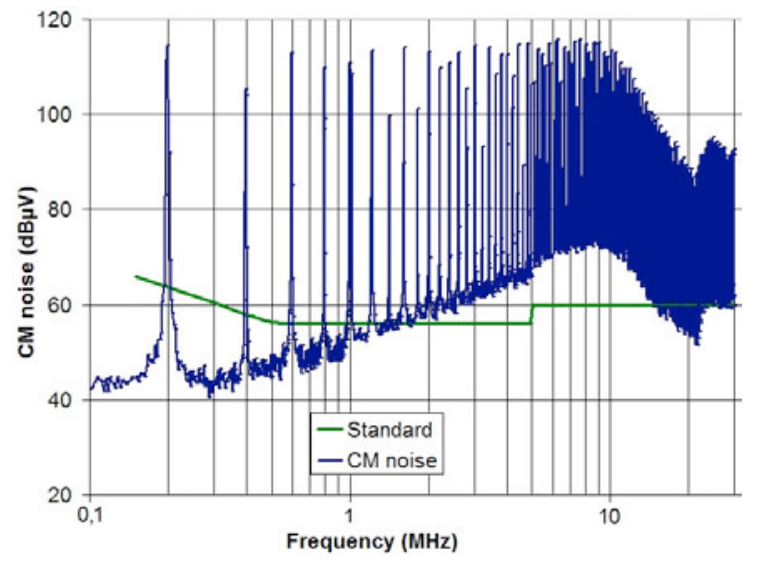

a. Common mode emissions

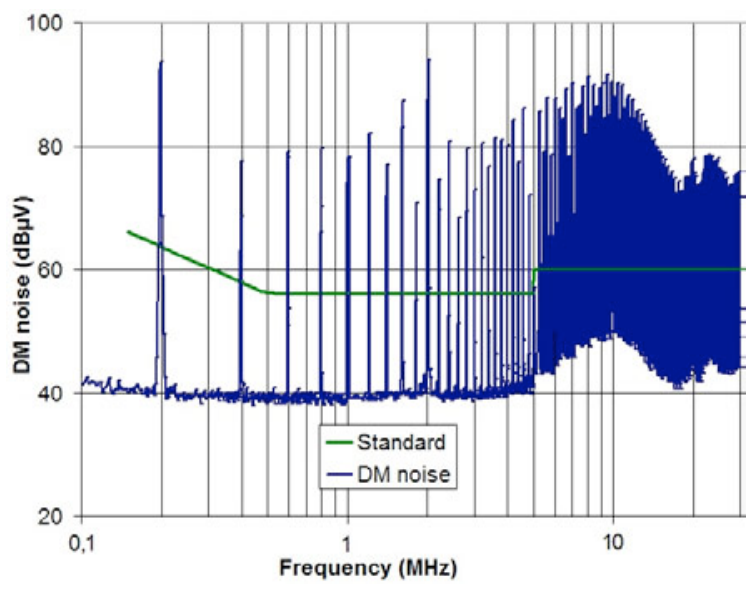

b. Differential mode emissions

Figure 5: The spectrum of the CM and DM currents

To design of the L-C structure filter, the slopes of \pm $40 \mathrm{~dB} /$ decade are drawn to determine the cutoff frequencies for each mode: $\mathrm{f}_{\mathrm{CM}}, \mathrm{f}_{\mathrm{CMH}}$ and $\mathrm{f}_{\mathrm{DM}}, \mathrm{f}_{\mathrm{DMH}}$. The filter elements are calculated from these cutoff frequencies as shown in Figure 6. As presented in [13], frequencies $\mathrm{f}_{\mathrm{CMH}}$ and $\mathrm{f}_{\mathrm{DMH}}$ are used to determine the limits of the parasitic elements of passive components.

To calculate the elements of the L-C common mode filter, the value of the capacitor is fixed to $C_{Y}=4.7 n F$. This value provides a good compromise; it is large enough to minimize the value of the $\mathrm{CM}$ inductor and small enough to limit ground currents to prevent accidental tripping of mains differential circuit breaker. The value of the CM inductor is :

$$
\mathrm{L}_{\mathrm{CM}}=\frac{1}{\left(2 \pi f_{C M}\right)^{2} \cdot 2 C_{Y}}=26.9 m H
$$

As shown in figure $6 \mathrm{a}$, the cutoff frequency is equal to $\mathrm{f}_{\mathrm{CM}}=10 \mathrm{kHz}$. For frequencies above $10 \mathrm{MHz}$ the $\mathrm{CM}$ inductor becomes capacitive (noted $\mathrm{Cf}$ ) and $\mathrm{C}_{\mathrm{Y}}$ capacitor becomes inductive ( $\mathrm{Lf}$ its value). For the used capacitor, its parasitic inductance $\mathrm{Lf}$ is equal to $60 \mathrm{nH}$. Knowing the high cutoff frequency $\mathrm{f}_{\mathrm{CMH}}=240 \mathrm{MHz}$ (figure $6 \mathrm{a}$ ), the minimum value for $\mathrm{Cf}$ is obtained as following:

$$
\mathrm{Cf}=\frac{1}{\left(2 \pi f_{C M H}\right)^{2} \cdot(L f / 2)}=14.6 p F
$$

It's well known that an inductor of $26.9 \mathrm{mH}$ with as low stray capacitance value equal to $14.6 \mathrm{pF}$ is very difficult to obtain. For this reason, T-filter structure is used with two inductors $\left(\mathrm{L}_{1}\right.$ and $\left.\mathrm{L}_{2}\right)$. This solution allows reducing the size of inductors and thus their stray capacitances. 


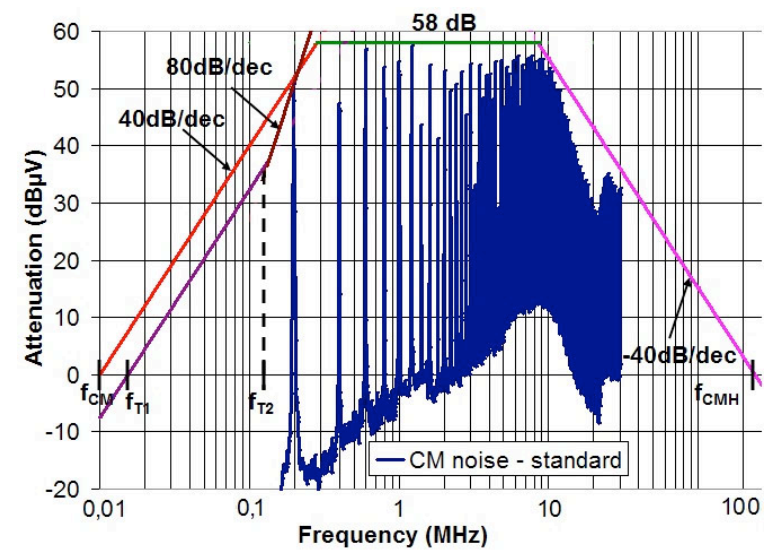

a. Common mode attenuation

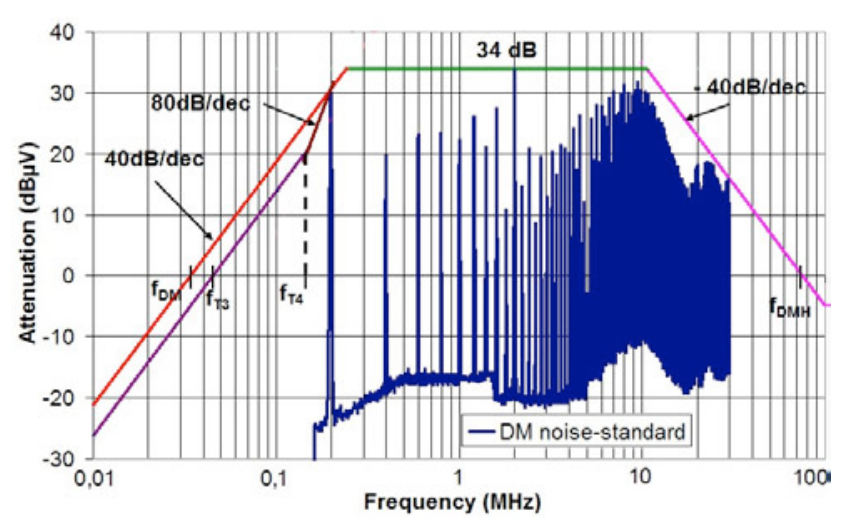

b. Differential mode attenuation

Figure 6: Determination of the common and differential attenuations of the filter.

In the following section, only the design of the common mode filter will be detailed. However, the design of the CM and DM filters is presented in the next section.

\subsection{Common mode filter}

The required attenuation value of common mode is $58 \mathrm{~dB}$, thus, a T-filter structure (L-C-L) is necessary. In order to study of this filter, it can be divided into two serial filters: $\mathrm{L}_{1} \mathrm{C}_{1}$ and $\mathrm{L}_{2} \mathrm{C}_{\mathrm{CM}}$. Here, $\mathrm{C}_{\mathrm{CM}}$ is the equivalent capacitance of all common mode couplings of the buck converter. The measured common mode impedance $Z_{\mathrm{CM}}$ shows that it has a capacitive behavior (corresponding to $Z_{1}$ in figure 8 ). The first slope of $40 \mathrm{~dB} /$ decade set the cutoff frequency $\mathrm{f}_{\mathrm{T} 1}=$ $15.5 \mathrm{kHz}$ of the first $\mathrm{L}_{1} \mathrm{C}_{1}$ filter and the second slope of 80 $\mathrm{dB} /$ decade set the cutoff frequency $\mathrm{f}_{\mathrm{T} 2}=136.5 \mathrm{kHz}$ of the second $\mathrm{L}_{2} \mathrm{C}_{\mathrm{CM}}$ filter (Figure 6a). In this case, the frequency $\mathrm{f}_{\mathrm{T} 1}>\mathrm{f}_{\mathrm{CM}}$ in order to minimize the value of $\mathrm{L}_{1}$ and the frequency $\mathrm{f}_{\mathrm{T} 2}<150 \mathrm{kHz}$ so that the line of slope $80 \mathrm{~dB} /$ decade is tangent to the required attenuation. The common mode impedance $\mathrm{Zp}$ of the converter was measured as shown in figure 8 . It can be modeled by an serial R-L- $\mathrm{C}_{\mathrm{CM}}$ circuit where the converter equivalent capacitance is equal to $\mathrm{C}_{\mathrm{CM}}=398 \mathrm{pF}$. By setting the values of the common mode capacitors $\mathrm{C}_{\mathrm{Y}}=4.7 \mathrm{nF}=\mathrm{C}_{1} / 2$. This value provides a good compromise; it is large enough to minimize the value of the CM inductors and small enough to limit ground currents to prevent accidental tripping of mains differential circuit breaker. we can calculate the values of the inductors $\mathrm{L}_{1}$ and $\mathrm{L}_{2}$ of the $\mathrm{T}$-filter by the following equations [14].

$$
\begin{aligned}
& L_{1}=\frac{1}{\left(2 \pi f_{T 1}\right)^{2} 2 C_{Y}}=\frac{1}{\left(2 \pi 15.5 .10^{3}\right)^{2} 9.4 .10^{-9}}=11.2 \mathrm{mH} \\
& L_{2}=\frac{1}{\left(2 \pi f_{T 2}\right)^{2} C_{C V}}=\frac{1}{\left(2 \pi 136.5 .10^{3}\right)^{2} 398.10^{-12}}=3.4 \mathrm{mH}
\end{aligned}
$$

From calculated values of $\mathrm{L}_{1}, \mathrm{~L}_{2}$ and $\mathrm{C}_{\mathrm{Y}}$, and limits given by the EMC standard (figure 6a), the proposed model of the $\mathrm{CM}$ filter is given in figure 7. It will be used for the simulation of the filter to evaluate the attenuation necessary that taking into account the limits values of the parasitic elements of the passive components (Rp1, Rp2, Cf1, Cf2, $\mathrm{Ry} / 2, \mathrm{Ly} / 2, \mathrm{Lf}, \mathrm{Rs}$ ) and CM impedance path Zp named "the second CM impedance path".

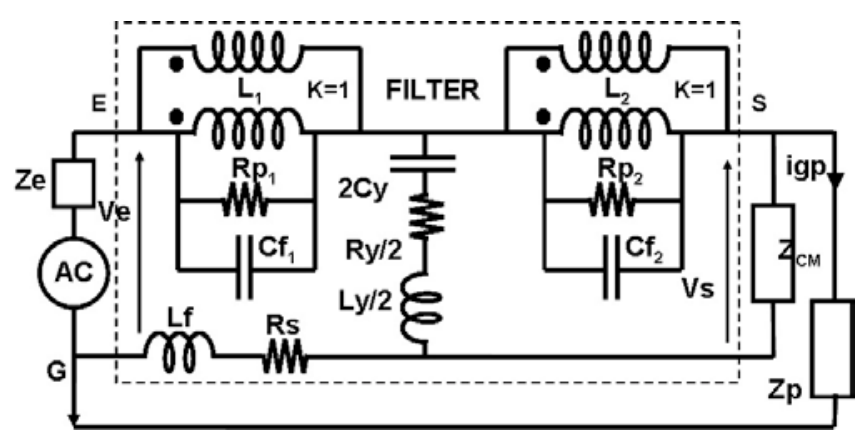

Figure 7: High frequency model of the CM filter

To use this model, it is necessary to measure the impedance $\mathrm{Ze}, \mathrm{Zp}, \mathrm{Z}_{\mathrm{CM}}$. These three impedances are measured by impedance analyzer (Agilent 4294A) when the converter is in off-state or by using the injection current probes method, which allows obtaining the buck converter impedance in operation conditions as described in [15]-[20]. The results of measurements are shown in Figures 8, 9, 10.

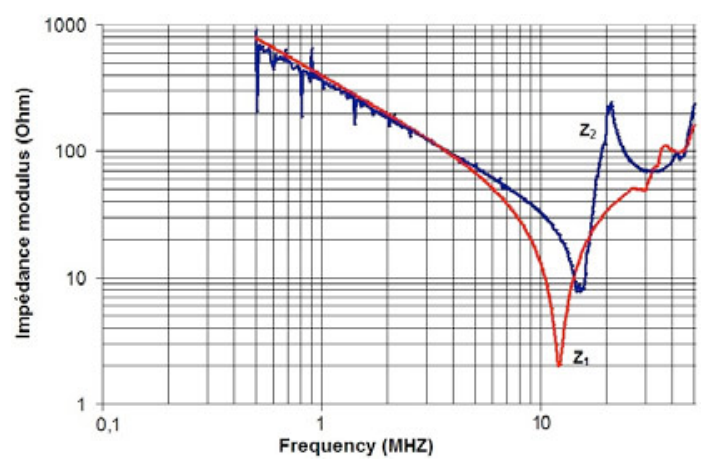

Figure 8: $\mathrm{Z}_{\mathrm{CM}}$ input impedance of the converter: $\mathrm{Z}_{1}$ with impedance analyzer (Buck in OFF-state), $Z_{2}$ with the injection current probes method of (converter ON-state) 
The impedance $\mathrm{Zp}$ is measured using an impedance analyzer between the points "G" of the LISN connected to the ground plane and the "S" input side of the converter (figure 7). In the first case, the EMI filter is not connected and the ground link between the LISN and the converter is disconnected. This configuration allows to measure the capacitive impedance $\mathrm{Zp}$ of the common mode path between the point "G" or "S" and the surrounding conductive parts (ie of the filter housing, the converter, its load and the ground plane). The CM impedance at the input side of the converter $Z_{\mathrm{CM}}$ measured between the 2 supply wire connected together and the ground wire (see fig 8).

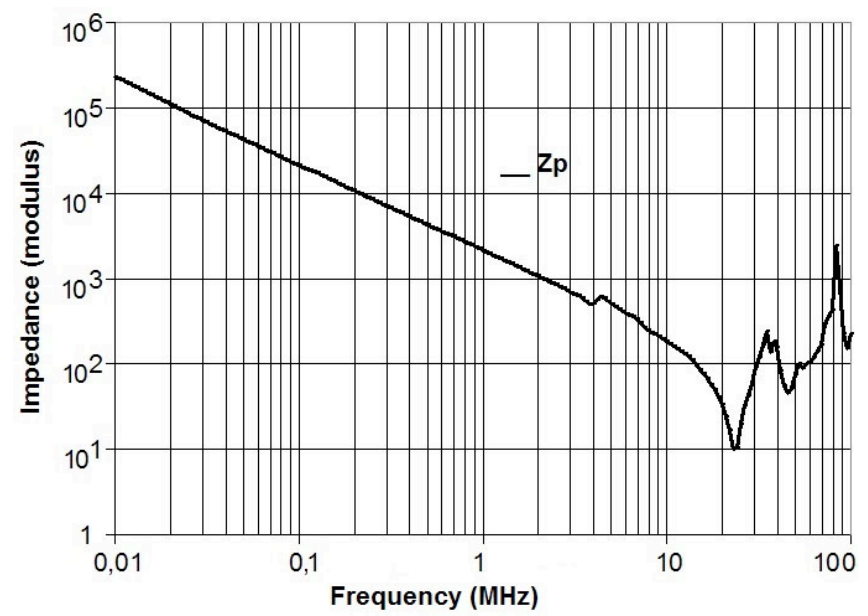

Figure 9: Measured impedance $\mathrm{Zp}$ without EMI filter.

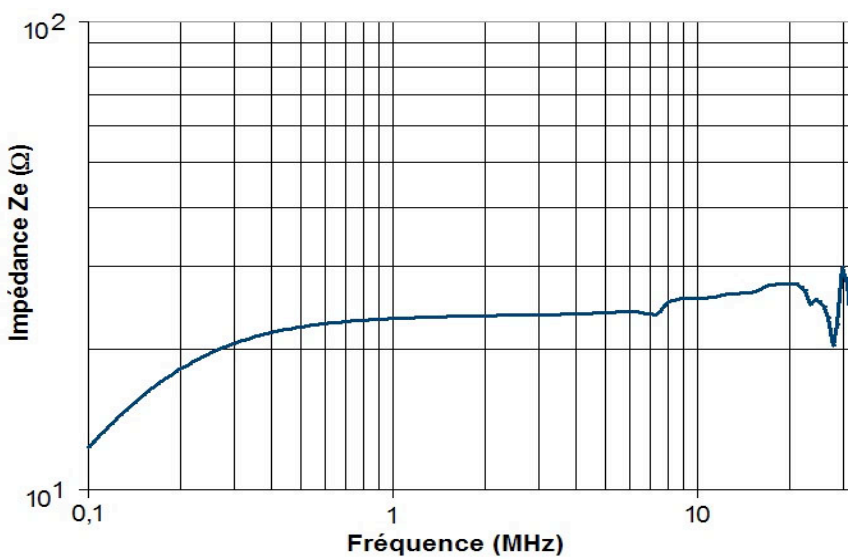

Figure 10: Measured impedance Ze of the LISN.

The connection impedance of the filter is taken into account the ground wire between the LISN and filter the PCB tracks. To simulate the filter, the various elements of the filter model are determined using the method described in [13], [18], [19]. The next step consists to determine the filter components mainly the chokes.

\subsubsection{Determination of the filter chokes}

In order to reduce parasitic capacitances $\mathrm{C}_{\mathrm{f} 1}$ of the inductors that appear in high frequency, we have chosen to make coil
$\mathrm{L}_{1}$ with 2 cores in series $\mathrm{L}_{1}=\mathrm{L}_{11}+\mathrm{L}_{12}$, as shown in figure 11 . The first inductor $\mathrm{L}_{11}$ uses nanocrystalline material and has 38 turns. The second inductor $\mathrm{L}_{12}$ uses ferrite (EPCOS-T37) material and has 27 turns. The third inductor core $\mathrm{L}_{2}$ uses ferrite material (EPCOS-N30) that is placed flat and has 28 turns. We used two ferrite cores for $\mathrm{L}_{12}$ and $\mathrm{L}_{2}$. Using the characteristics of the magnetic material datasheets, inductor values are given in table 1 :

Table 1: Inductor values

\begin{tabular}{|c|c|c|}
\hline $\mathrm{L}_{11}$ & $\mathrm{~L}_{12}$ & $\mathrm{~L}_{2}$ \\
\hline $20 \mathrm{mH}$ & $5.4 \mathrm{mH}$ & $3.4 \mathrm{mH}$ \\
\hline
\end{tabular}

The measured value of $\mathrm{L}_{1}$ is more important than calculated one. One can notice that the measured value (which uses the nanocrystalline core) decreases rapidly in frequency band varying from $10 \mathrm{kHz}$ to $800 \mathrm{kHz}$.

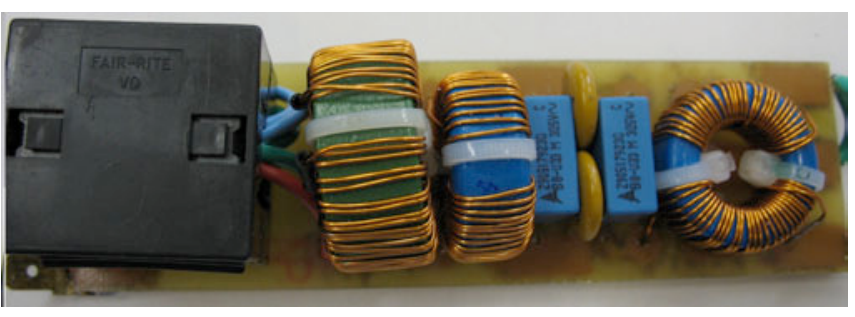

Figure 11: EMI filter realized.

To obtain the required attenuation, it is necessary to perform simulations that require high accuracy models of the inductors. Two inductors of the filter are realized, their high frequency parameters are measured using the method proposed in [16], [17]. In the table 2 are given the measured values of various elements of the filter that will be used in the simulation.

Table 2: Filter model parameters.

\begin{tabular}{|c|c|c|c|c|c|}
\hline $\mathrm{Ze}$ & $Z_{\mathrm{ch}}$ & $\mathrm{L}_{1}$ & $\mathrm{C}_{\mathrm{f} 1}$ & $\mathrm{R}_{\mathrm{p} 1}$ & $\mathrm{~L}_{2}$ \\
\hline $25 \Omega$ & $\mathrm{Z}_{1}$ & $25.4 \mathrm{mH}$ & $2.5 \mathrm{pF}$ & $41 \mathrm{k} \Omega$ & $3.4 \mathrm{mH}$ \\
\hline $\mathrm{C}_{\mathrm{f} 2}$ & $\mathrm{Rp}_{2}$ & $\mathrm{C}_{2 \mathrm{Y}}$ & $R_{Y / 2}$ & $\mathrm{~L}_{\mathrm{Y} / 2}$ & Rs \\
\hline $4 \mathrm{pF}$ & $20.3 \mathrm{k} \Omega$ & $9.4 \mathrm{nF}$ & $0.5 \Omega$ & $30 \mathrm{nH}$ & $0.2 \Omega$ \\
\hline $\mathrm{L}_{\mathrm{f}}$ & $\mathrm{Rp}$ & $\mathrm{Lp}$ & $\mathrm{Cp}$ & & \\
\hline $0.04 \mu \mathrm{H}$ & $2 \Omega$ & $1 \mu \mathrm{H}$ & $75 \mathrm{pF}$ & & \\
\hline
\end{tabular}

The values of the parasitic capacitances of the inductors, $\mathrm{C}_{\mathrm{f} 1}$ and $\mathrm{C}_{\mathrm{f} 2}$ are very low. To carry out these measurements in operating conditions, we used a power amplifier (200V peak to peak) between $1 \mathrm{MHz}$ and $30 \mathrm{MHz}$. Figure 12 shows the principle of the proposed measurement method. In this case, measurements of the voltage and the current are made with an oscilloscope. 


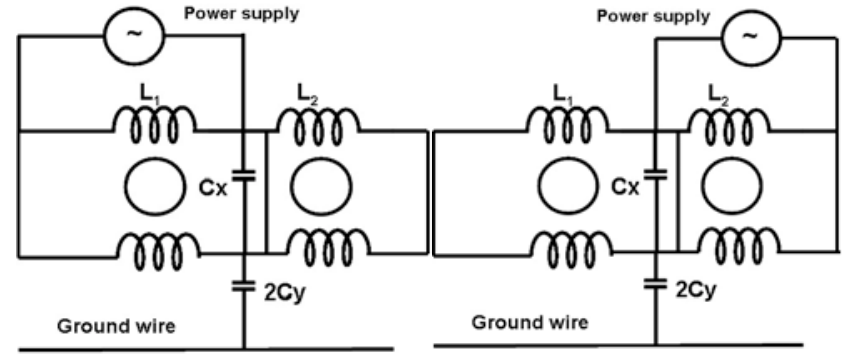

Figure 12: Measure of parasitic capacitances $\mathrm{C}_{\mathrm{f} 1}$ and $\mathrm{C}_{\mathrm{f} 2}$.

Table 3 shows the values of the obtained parasitic capacitances:

Table 3: Parasitic capacitance values

\begin{tabular}{|c|c|}
\hline $\mathrm{C}_{\mathrm{f} 1}$ & $\mathrm{C}_{\mathrm{f} 2}$ \\
\hline $14.9 \mathrm{pF}$ & $30.8 \mathrm{pF}$ \\
\hline
\end{tabular}

\subsubsection{Determination of insertion loss by simulation}

These values are used in the model shown in figure 7 . They will be used to calculate the required $\mathrm{CM}$ attenuation of the filter using the measured common mode impedance $Z_{1}$ of Buck shown in figure 8 where $\mathrm{Re}=25 \Omega$ corresponds to the equivalent CM resistance of the LISN. Figure 13 shows a comparison of the $\mathrm{CM}$ filter attenuation measured and obtained by simulation using the proposed model. The curves obtained by simulation are calculated by the formula: Noise level - EMC Standard limit (EN55011).

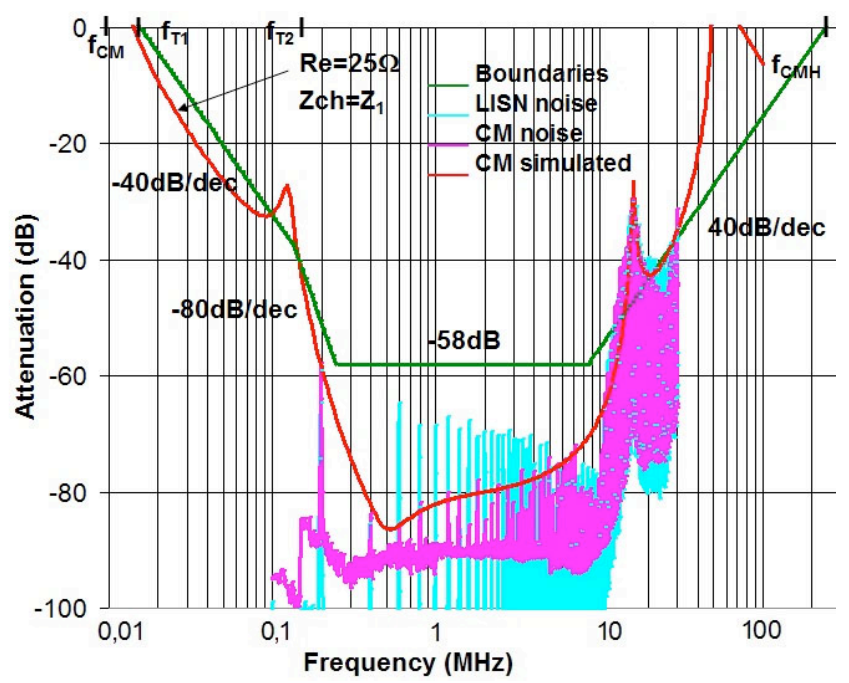

Figure 13: Comparison of the CM attenuation of the filter measured and simulation.

The attenuation complies with the limits given by EMC standards in the frequency band between $150 \mathrm{kHz}$ and $30 \mathrm{MHz}$, except for a high frequency band between $12.3 \mathrm{MHz}$ and $21.4 \mathrm{MHz}$. This result shown that, at $16 \mathrm{MHz}$, the maximum value reached $17 \mathrm{~dB}$. To increased the attenuation of the filter, a NiZn core is placed around the three power wires: 2 supply wires plus the ground wire. One can note that this solution allowed reducing the second common mode path that corresponds mainly to the ground plane path. The NiZn ferrite core induced additional resistance $R_{N}$ and reactance $X_{N}$ through the second CM path. We used the schematic of figure 14 to calculate these elements. To simplify the simulation circuit, these elements are directly linked in series with the ground wire.

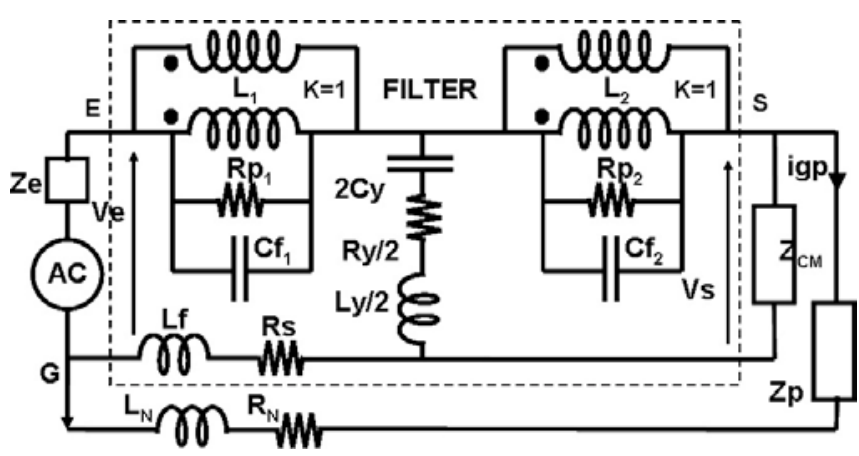

Figure 14: High frequency model of the CM filter

As well known, the parameters of the wire $\left(R_{N}\right.$ and $\left.X_{N}\right)$ are varying with the frequency. On Figure 15 are given the evolution of the elements $\mathrm{R}_{\mathrm{N}}$ and $\mathrm{X}_{\mathrm{N}}$ with frequency for two turns around the NiZn ferrite core used as CM filter.

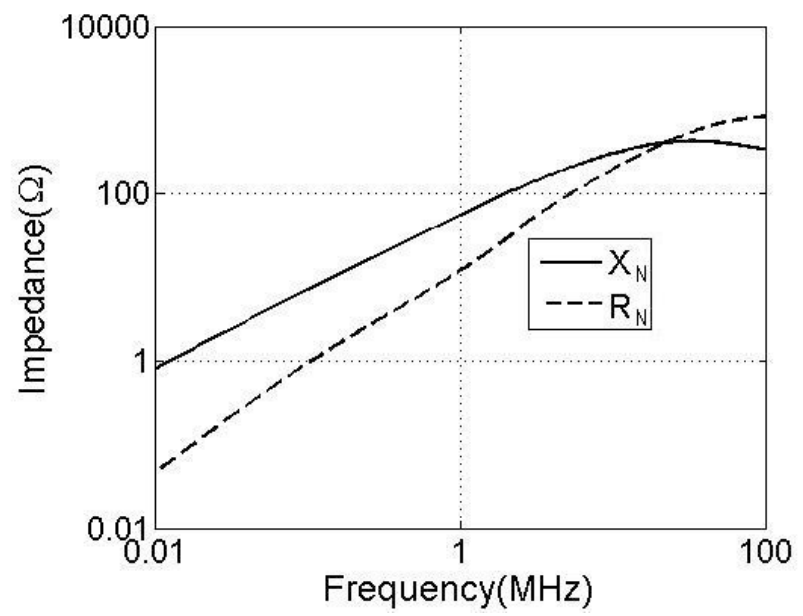

Figure 15: Measured of $\mathrm{R}_{\mathrm{N}}$ and $\mathrm{X}_{\mathrm{N}}$ elements.

The obtained model of the filter is simulated and the obtained result of the $\mathrm{CM}$ filter attenuation is shown in figure 16. This result corresponds to the measured attenuation of the CM filter when the NiZn core is place around the three power lines. Finally, the simulation result of the attenuation of the filter is compared to the measurement and which shows a good agreement. 


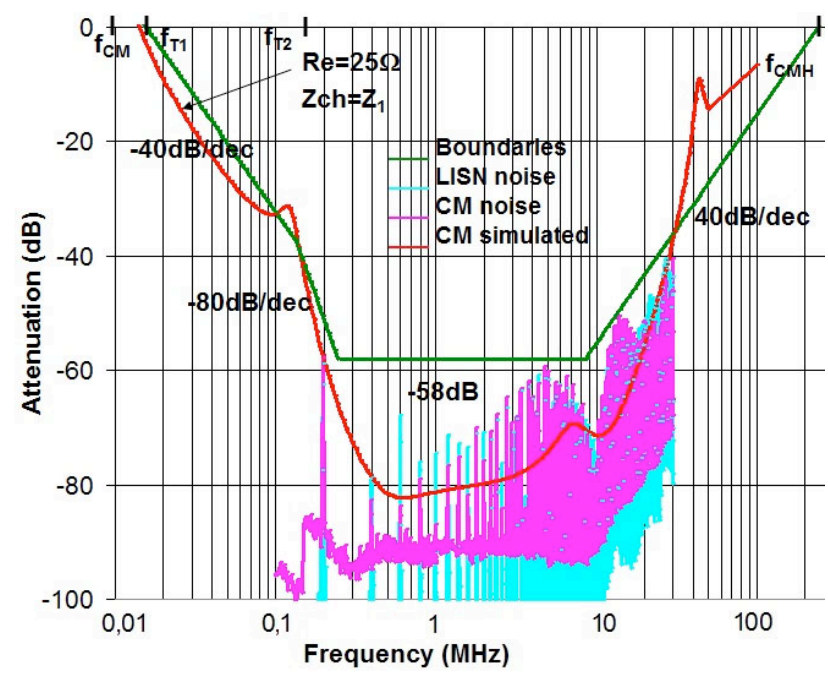

Figure 16: Comparison of the $\mathrm{CM}$ filter attenuation measured and simulate when the NiZn core around the three power wires.

\subsection{Differential mode filter}

The previously method is used to design the differential mode filter. The required attenuation for this filter is equal to $34 \mathrm{~dB}$. The T-filter structure is used and it can divide into two cascade filters: $2 \mathrm{~L}_{1 \mathrm{MD}} \cdot \mathrm{C}_{\mathrm{X}}$ and $2 \mathrm{~L}_{2 \mathrm{MD}} \cdot \mathrm{C}_{\mathrm{DM}}$. Where, the $\mathrm{C}_{\mathrm{DM}}$ capacitor corresponds to the DC bus converter which equal to $\mathrm{C}_{\mathrm{DM}}=100 \mathrm{nF}$.

The first slope of $40 \mathrm{~dB} /$ decade determine the cut-off frequency $\mathrm{f}_{\mathrm{T} 3}=45 \mathrm{kHz}$ of the first filter $2 \mathrm{~L}_{1 \mathrm{MD}} \cdot \mathrm{C}_{\mathrm{X}}$ and the second slope of $80 \mathrm{~dB} /$ decade allows to obtain the second cut-off frequency $\mathrm{f}_{\mathrm{T} 4}=150 \mathrm{kHz}$ of the second filter $2 \mathrm{~L}_{2 \mathrm{MD}} \cdot \mathrm{C}_{\mathrm{DM}}$ (Figure 6b). Then, $\mathrm{f}_{\mathrm{T} 3}>\mathrm{f}_{\mathrm{DM}}$ is chosen to minimize the value of $\mathrm{L}_{1 \mathrm{MD}}$ and $\mathrm{f}_{\mathrm{T} 4} \leq 150 \mathrm{kHz}$ so that the line of slope $80 \mathrm{~dB} /$ decade is tangent to the required attenuation. By fixing the values of the differential mode capacitors at $C_{X}=660 \mathrm{nF}$, we can calculate the values of the inductors $\mathrm{L}_{1 \mathrm{MD}}$ and $\mathrm{L}_{2 \mathrm{MD}}$ of $\mathrm{T}$ filter using the following equations [14].

$$
\begin{aligned}
& L_{1 M D}=\frac{1}{\left(2 \pi f_{T 3}\right)^{2} 2 \cdot C_{X}}=\frac{1}{\left(2 \pi \cdot 45 \cdot 10^{3}\right)^{2} \cdot 660 \cdot 10^{-9}}=19 \mu \mathrm{H} \\
& L_{2 M D}=\frac{1}{\left(2 \pi f_{T 4}\right)^{2} \cdot C_{D M}}=\frac{1}{\left(2 \pi \cdot 150 \cdot 10^{3}\right)^{2} \cdot 100 \cdot 10^{-9}}=11.3 \mu \mathrm{H}
\end{aligned}
$$

In this case, values of 2. $\mathrm{L}_{2 \mathrm{MD}}$ and $2 . \mathrm{L}_{1 \mathrm{MD}}$ correspond to leakage inductances of $C M$ inductors $L_{1}$ and $L_{2}$. The values of leakage inductance of the $\mathrm{CM}$ inductors are measured to ensure that they are greater than the calculated values (7), (8).

The measured leakages values are: $2 . \mathrm{L}_{2 \mathrm{MD}}=33.2 \mu \mathrm{H}$ and 2. $\mathrm{L}_{1 \mathrm{MD}}=89.6 \mu \mathrm{H}$. Thus, we have:

$$
\begin{aligned}
& \text { 2. } \mathrm{L}_{1 \mathrm{MD}}=38 \mu \mathrm{H}<89.6 \mu \mathrm{H} \\
& \text { 2. } \mathrm{L}_{2 \mathrm{MD}}=22.6 \mu \mathrm{H}<33.2 \mu \mathrm{H}
\end{aligned}
$$

The measured values are greater than calculated values, so that the DM attenuation is validated. In the following section, the influence of the impedance paths of the common mode current will be study.

\section{Identification of the impedance paths}

The first step before to design the filter is the identification of the different common mode and differential mode impedances that corresponds to the impedances paths of the study system. The experimental results show that the installation of filter will change the propagation paths of the common mode currents. For this raison, it's necessary to indentify the various common mode paths of the system before the design of the filter. Thus, two identification steps are necessary: the identification of the disturbance current paths and their impedances without and with the EMI filter. In the following section, only the common mode impedance is considered. However, the same approach can be applied to the identification of the differential mode impedance paths. It should be noted that contrary to what is often done, the proposed method is based on measurements made in the time domain.

\subsection{Disturbance current paths without filter}

To design the filter it's necessary to measure separately the common mode and differential mode currents. In this study, current probes (FCC-F35-100MHz) are used to measure the common mode current $\mathrm{i}_{\mathrm{CM}}$ of the converter at the input side of the converter as shown in figure 17.

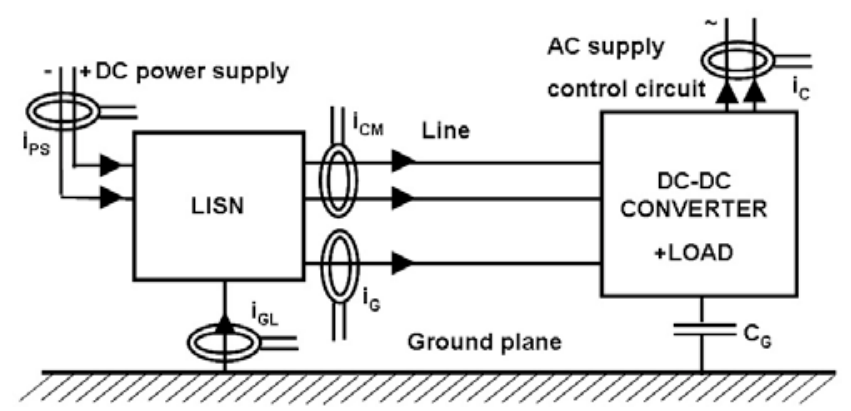

Figure 17: Common mode current measurements.

The waveforms of the various CM currents in the system are shown in figure 18 to 20 . Using the nodes law, the different currents in the system are expressed by the following relation (9):

$$
\mathrm{i}_{\mathrm{GL}}+\mathrm{i}_{\mathrm{PS}}=\mathrm{i}_{\mathrm{CM}}+\mathrm{i}_{\mathrm{G}}
$$

where:

$\mathrm{i}_{\mathrm{PS}}$ : common mode current in the DC power supply,

$\mathrm{i}_{\mathrm{CM}}$ : common mode current in the line between LISN and the converter,

$\mathrm{i}_{\mathrm{G}}$ : common mode current in the ground wire between LISN and converter, 
$\mathrm{I}_{\mathrm{GL}}$ : common mode current flowing in the ground plane, $\mathrm{i}_{\mathrm{C}}$ : common mode current in the AC power supply of control circuit.

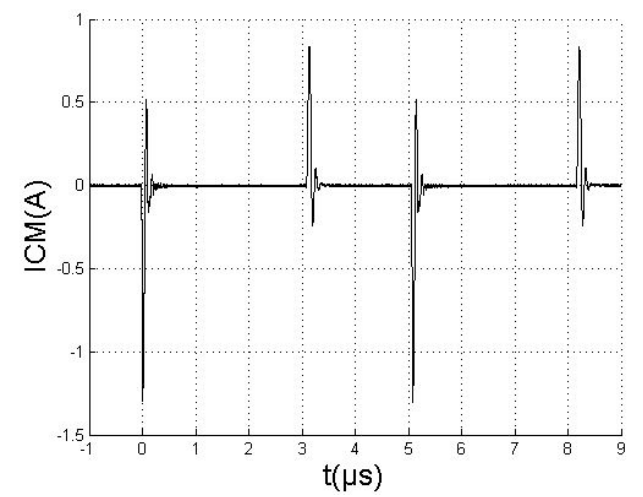

Figure 18: Experimental waveform of the current $\mathrm{i}_{\mathrm{CM}}$.

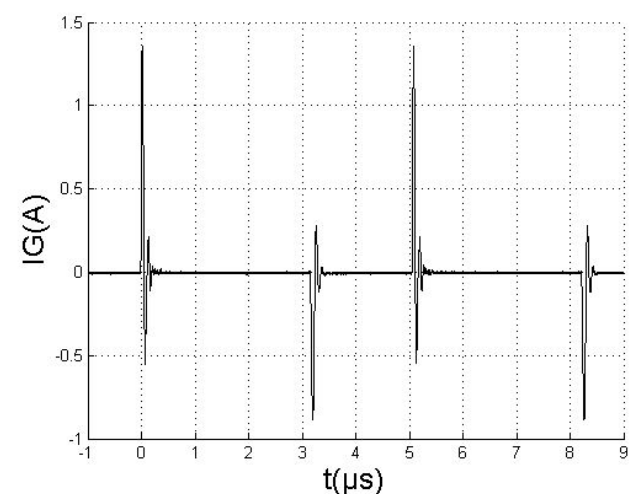

Figure 19: Experimental waveform of the current $i_{G}$.

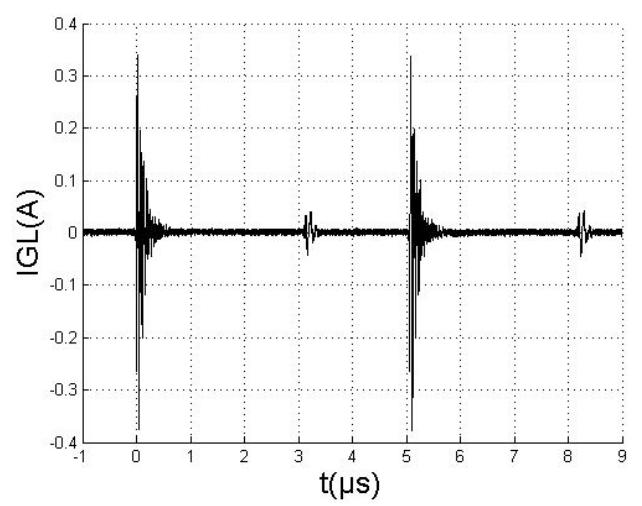

Figure 20: Experimental waveform of the current $\mathrm{i}_{\mathrm{GL}}$.

The waveforms of currents $I_{P S}$ and $i_{C}$ show that their amplitudes are less than 20 times that of $\mathrm{i}_{\mathrm{CM}}$ and $\mathrm{i}_{\mathrm{G}}$. The peak current amplitude $i_{P S}$ is not totally significant because it represents $1 / 8$ of $i_{\mathrm{G}}$. However, the instantaneous value of $\mathrm{i}_{\mathrm{CM}}$ is very close to $-\mathrm{i}_{\mathrm{G}}$. Using the reciprocity principle, the equivalent circuit for the considered system can be represented by the equivalent circuit shown in figure 21 . In this circuit, the following impedances are used: LISN impedance $(\mathrm{Ze})$, the common mode impedance of the converter $(\mathrm{Zcmcv})$, impedance of the two line wires $\left(\mathrm{Z}_{\mathrm{CML}}\right)$ between LISN and the converter, the ground wire $\left(Z_{G}\right)$ and two line wires capacitance $\mathrm{C}_{\mathrm{CML}}$. The currents are such as $\mathrm{i}_{\mathrm{CM}}=-\mathrm{i}_{\mathrm{G}}$. The disturbance source is represented by $\mathrm{AC}$ generator.

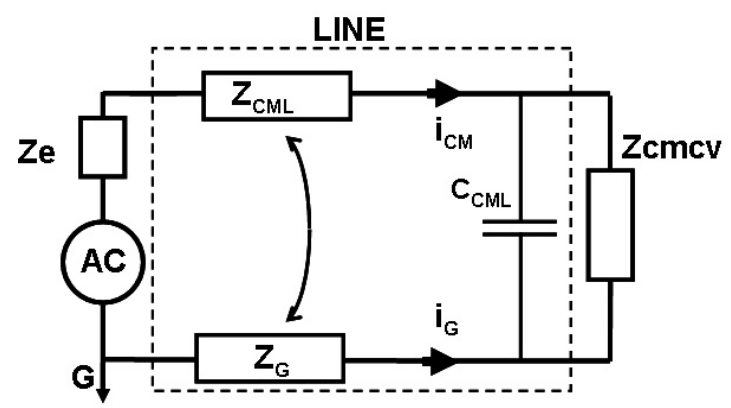

Figure 21: Equivalent circuit of the common mode current paths.

\subsection{Disturbance current paths with EMI filter}

Figure 22 shows the new configuration of the considered system with the EMI-filter. As presented above, the various common mode current waveforms of the system are measured when the NiZn core is not yet placed around the three power lines (noted HF ferrite core).

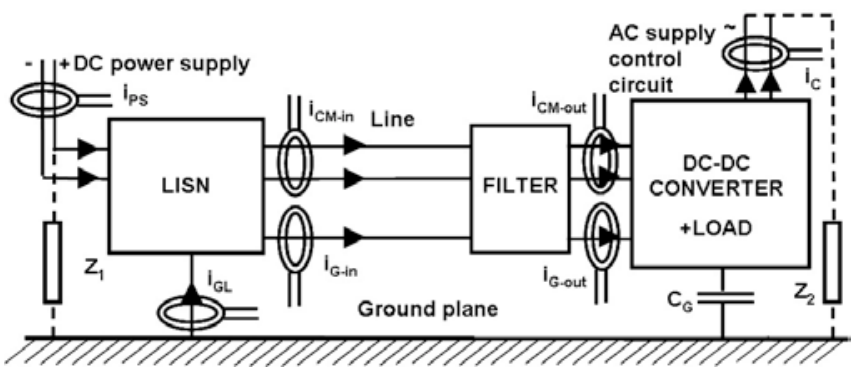

Figure 22: Setup CM current measurements with EMI filter.

The experimental results show that the distribution of the $\mathrm{CM}$ currents in the system is strongly modified. Figures 23 to 25 show the different waveforms of the CM currents.

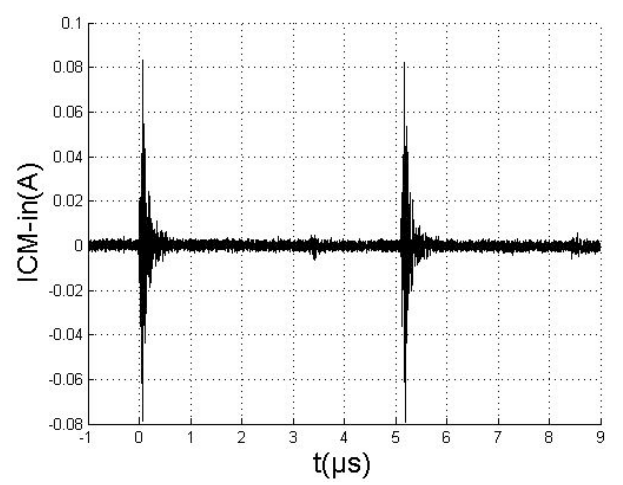

Figure 23: Experimental waveform of the current $\mathrm{i}_{\mathrm{CM} \text {-in }}$. 


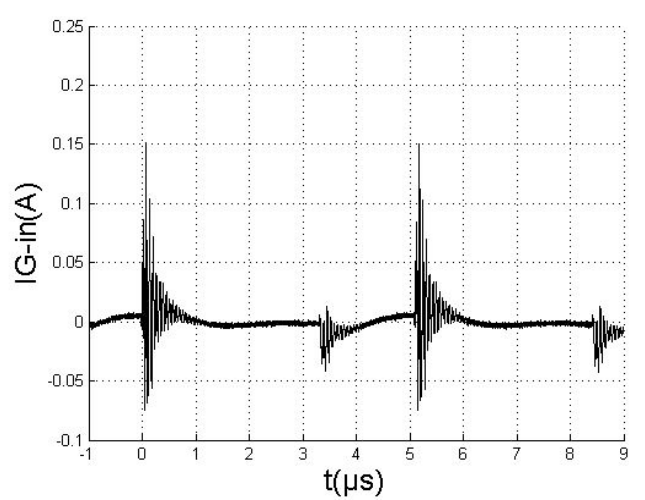

Figure 24: Experimental waveform of the current $\mathrm{i}_{\mathrm{G}-\mathrm{in}}$.

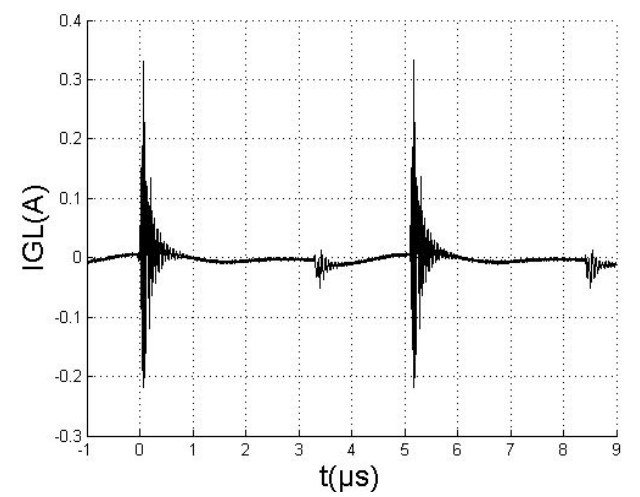

Figure 25: Experimental waveform of the current $\mathrm{i}_{\mathrm{GL}}$.

\subsection{Disturbance current paths with complete filter}

In order to study the influence of the complete filter structure (T-filter with HF ferrite core) the different measurements are carried out. Figures 26 to 28 show the different currents waveforms with CM and DM filter plus the HF ferrite core. These results show that globally, the maximum values of these current are decreased in comparison with the previously case. However, the frequencies of the oscillations have increased which justify that the perturbations are moved towards the high frequencies.

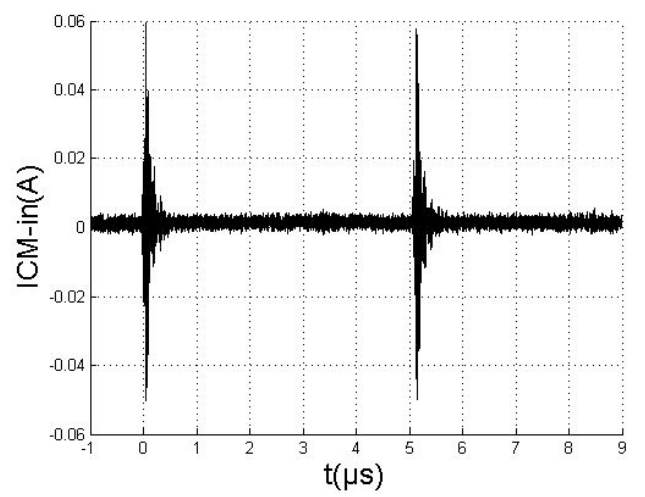

Figure 26: Experimental waveform of the current $\mathrm{i}_{\mathrm{CM} \text {-in }}$.

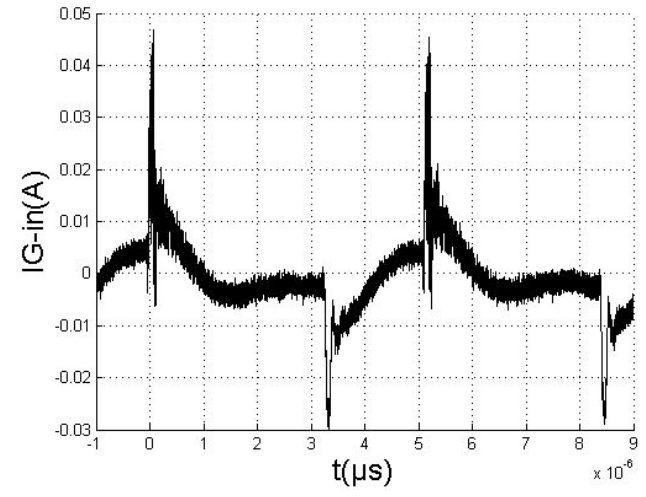

Figure 27: Experimental waveform of the current $\mathrm{i}_{\mathrm{G}-\mathrm{in}}$.

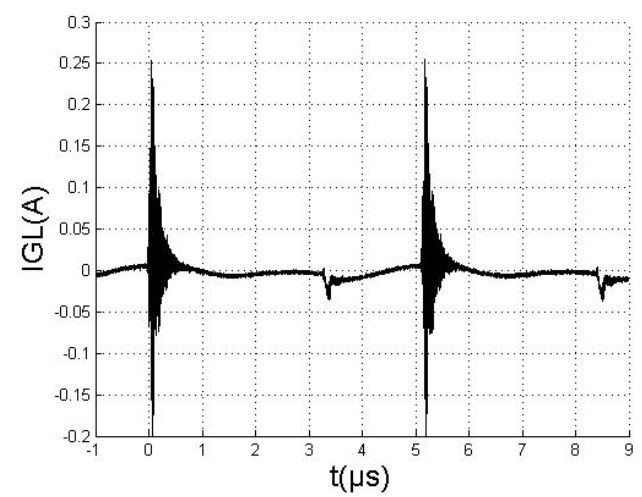

Figure 28: Experimental waveform of the current $\mathrm{i}_{\mathrm{GL}}$.

\subsection{Identification of the $C M$ paths}

To identify the different CM paths of the system, the peak current values at various points (wires) of the system are measured. Thus, figures 29 to 31 show the peak current values for three $\mathrm{CM}$ test configurations: without the filter (figure 29), with CM and DM filter (figure 30) and with $\mathrm{CM}$ and DM plus HF ferrite core (figure 31). In the first case (without the EMI filter), the CM current $\mathrm{i}_{\mathrm{CM} 1}$ go through the ground and returns by the power line as shown in figure 32. The magnitude of this current is very important and it is greatly reduced by the CM and DM filters without the HF ferrite core. However, the CM current $\mathrm{I}_{\mathrm{GL}}$ is equal to $\mathrm{I}_{\mathrm{CM} 2}$ which corresponds to the CM current through the ground plane. It is in the same direction of the 3 wires connected to the filter ( 2 wires of power line $\mathrm{i}_{\mathrm{CM} 21}$ and the ground line $\mathrm{i}_{\mathrm{CM} 2 \mathrm{G}}$ ), as shown in figure 32 . The $\mathrm{HF}$ ferrite core must be through by three wires from LISN for effectively reduced the $\mathrm{CM}$ current $\mathrm{i}_{\mathrm{CM} 2}$. Therefore the $\mathrm{i}_{\mathrm{CM} 2}$ current value is decreased from $0.33 \mathrm{~A}$ to $0.25 \mathrm{~A}$. 


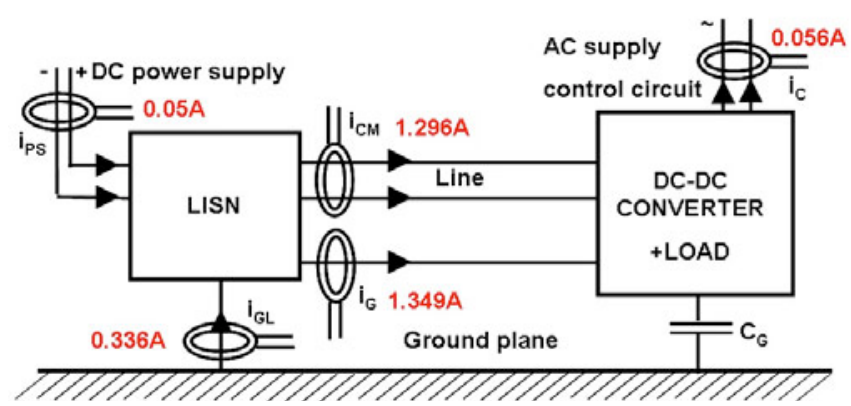

Figure 29: Maximum values of CM currents without filter.

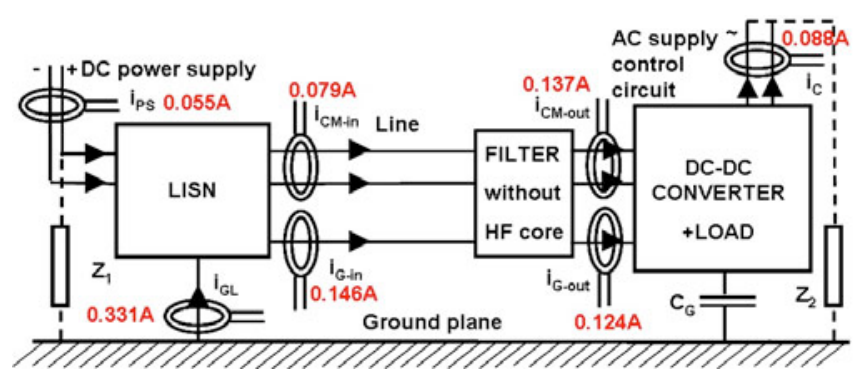

Figure 30: Maximum values of $\mathrm{CM}$ currents with $\mathrm{CM}$ and DM filter (without HF ferrite core).

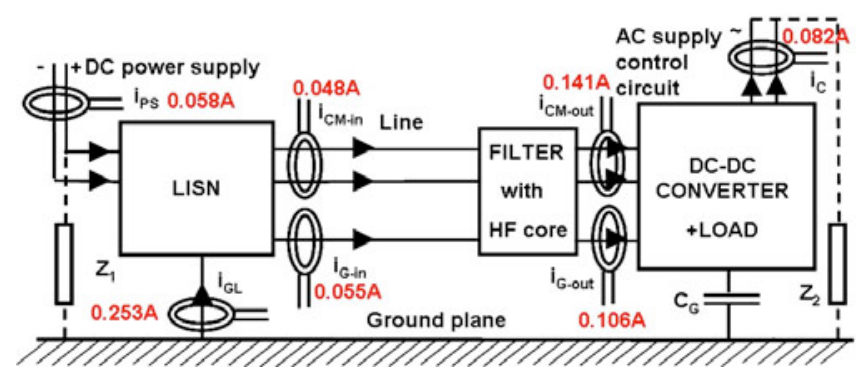

Figure 31: Maximum values of CM currents with $\mathrm{CM}$ and DM filter (plus HF ferrite core).

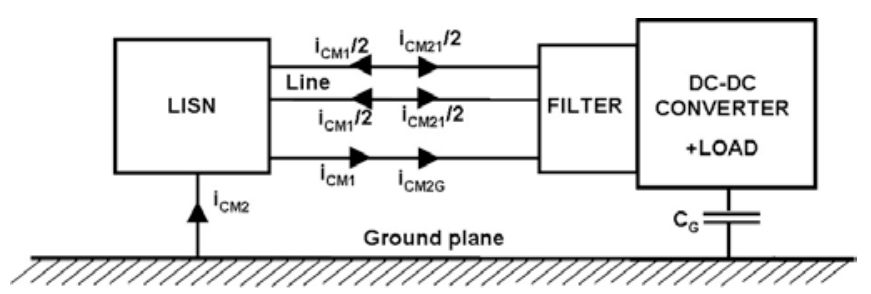

Figure 32: Distribution of the propagation paths of the two CM currents.

\section{Experimental results}

The experimental setup presented previously is used to validate the obtained results based on the proposed design method of the EMI filter. Figure 33 presents the spectrum of the conducted emissions using the LISN in different configurations:

- Without filter

- With CM and DM filter without filter

- With CM and DM filter plus HF ferrite core (with complete filter)

These results show that the HF ferrite core has a big influence on the reduction of the conducted emissions in high frequency band. The realized filter allowed reducing the conducted emissions induced by the SiC-Buck and compliance with EMC-Standards.

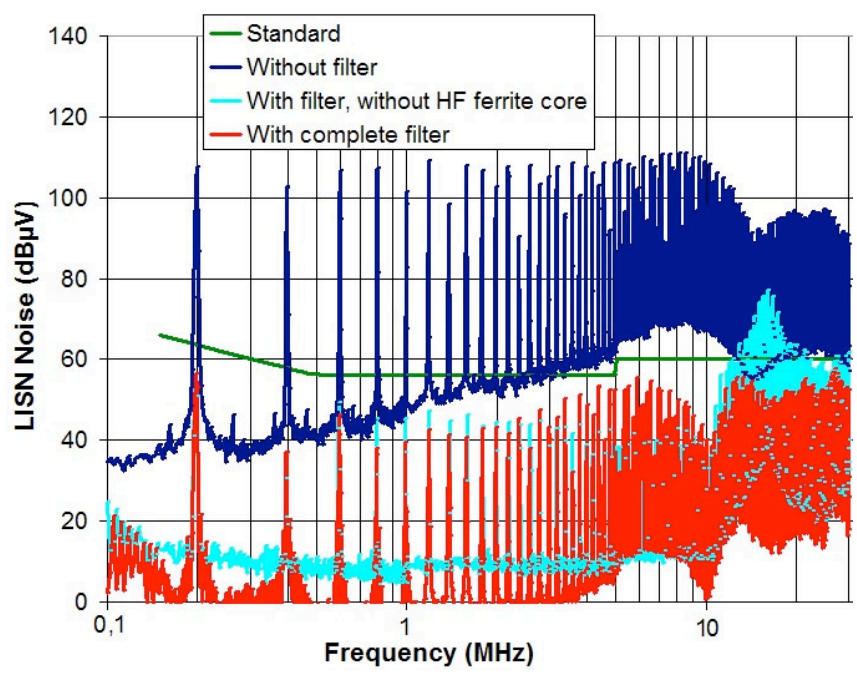

Figure 33: Comparison of conducted emissions in three configuration tests.

\section{Conclusions}

In this paper, a design method of the EMI filter used with DC-DC converter is presented. Two aspects are considered in this paper. The first aspect is related to the development of a methodology allowing to determine, in the first approach, the different values of the CM and DM filters, but also the limit values of the parasitic elements of passive components that have negative effect on the filter efficiency in high frequency. A solution is proposed for reduce the high frequency disturbances beyond the $10 \mathrm{MHz}$, which consists to use the NiZn ferrite core on three input wires of the filter. The second aspect is related to the development of the filter model which takes into account of an additional impedance $Z_{\mathrm{P}}$ which corresponding to second $\mathrm{CM}$ path (ground plane) often neglected in the design of the EMI filters. The experimental validation of this study shows that the obtained filter allows reducing the conducted emissions induced by the SiC-Buck converter and compliance with EMC-Standards. 


\section{References}

[1] D. A. Weston, "Electromagnetic compatibility: Principles and applications", Ed. Marcel Dekker, New York, 2001.

[2] G. Laimer, J.W. Kolar, "'Zero'-ripple EMI input filter concepts for application in a $1-U 500 \mathrm{kHz} \mathrm{Si} / \mathrm{SiC}$ threephase PWM rectifier", Telecommunications Energy Conference, 2003. INTELEC '03. The 25th International; Power, Energy, \& Industry Applications, Page(s): 750 - 756.

[3] X. Gong, J. A. Ferreira, J. Popovic-Gerber," Comparison and suppression of conducted EMI in SiC JFET and Si IGBT based motor drives", Power Electronics and Motion Control Conference (EPE/PEMC), 15th International, 2012.

[4] R. Robutel, C. Martin, H. Morel, P. Mattavelli, D. Boroyevitch, R. Meuret, N. Gazel, "Integrated common mode capacitors for SiC JFET inverters", Applied Power Electronics Conference and Exposition (APEC), 2011 Twenty-Sixth Annual IEEE, Power, Energy, \& Industry Applications, Page(s): 196 - 202.

[5] X. Gong, .I Josifovi'c, J. A. Ferreira, "Modeling and Reduction of Conducted EMI of Inverters With SiC JFETs on Insulated Metal Substrate", IEEE Transactions on Power Electronics, Vol. 28, No. 7, July 2013.

[6] X. Gong, .I Josifovi'c, J. A. Ferreira, "Modeling and Reduction of Conducted EMI of Inverters With SiC JFETs on Insulated Metal Substrate", IEEE Transactions on Power Electronics, Vol. 28, No. 7, July 2013.

[7] X. Gong, J. A. Ferreira, "Modeling and reduction of conducted EMI in SiC JFET motor drives with insulated metal substrate", Energy Conversion Congress and Exposition (ECCE), 2012 IEEE, Power, Energy, \& Industry Applications, Page(s): 629 - 636.

[8] H. Akagi, H. Hasegawa, T. Doumoto, "Design and performance of passive EMI filter for use with a voltage-source PWM inverter having sinusoidal output voltage and zero common-mode voltage", IEEE Transactions on Power Electronics, vol.19, $\mathrm{N}^{\circ} 4$, july 2004, pp.1069-1076.

[9] A. Roch, H. Bergsma, F. B. J. Leferink, "Design of an EMI Output Filter for Frequency Converter", in Proc. EMC Europe International Symposium on EMC, Barcelona, Spain, 2006.

[10]W. Xiaofeng, X. Dehong, Z. Yanjun, C. Yi, O. Yasuhiro, M. Kazuaki, "Integrated EMI Filter Design with Flexible PCB Structure", IEEE Power Electronics Society, PESC08, Rhodes, Greece, June 15-19 2008, CD proceeding, pp. 1613-1617.

[11] H. Chen, Z. Qian, Z. Zeng and C. Wolf, "Modeling of parasitic inductive couplings in a Pishaped common mode EMI filters", IEEE Trans. On Electromagnetic Compatibility, Vol.50 N¹, February 2008.
[12] J.L. Kotny, T. Duquesne, N. Idir, "EMI Filter design using high frequency models of the passive components", IEEE Workshop on Signal Propagation on Interconnects (SPI 2011), 8 -11 may 2011, Naples, Italy, 5-2011.

[13]J.L. Kotny, T. Duquesne, N. Idir, "Méthode de dimensionnement d'un filtre CEM pour un convertisseurs utilisant des composants SiC", Colloque International et Exposition sur la Compatibilité Electromagnétique - Rouen- CEM 2012.esigelec-25-26 et 27 Avril 2012.

[14]F. Y. Shih, D. Y. Chen, Y. P. Wu, and Y. T. Chen, "A procedure for designing EMI filters for $\mathrm{AC}$ line applications," IEEE Trans. Power Electron, Vol. 11, N 1, pp.170-181, 1996.

[15] V. Tarateeraseth, Bo Hu, Kye Yak See, F. G. Canavero, "Accurate Extraction of Noise Source Impedance of an SMPS Under Operating Conditions", IEEE Transactions on Power Electronics, Vol. 25, No. 1, January 2010.

[16] J.L. Kotny, T. Duquesne, N. Idir, J.L. Kotny, X. Margueron, N. Idir: "High Frequency Model of the coupled inductors used in EMI Filters". IEEE Transactions on Power Electronics - Vol. 27, $\mathrm{N}^{\circ} 6$, pp 2805-2812, 6-2012.

[17] J.L. Kotny, X. Margueron, N. Idir "High Frequency Modeling Method of EMI filters". IEEE Energy Conversion Congress and Exposition - ECCE09, 20-24 Septembre 2009, San Jose, Californie, USA.

[18] A. Majid, J. Saleem, K. Bertilsson, "EMI filter design for high frequency power converters" Environment and Electrical Engineering (EEEIC), 2012 11th International Conference on. Pages : 586-589, DOI :10.1109/ EEEIC. 2012.6221444 IEEE Conference Publications.

[19] Ruxi Wang, H.F. Blanchette, D. Boroyevich, P. Mattavelli, "EMI noise attenuation prediction with mask impedance in motor drive system", Applied Power Electronics Conference and exposition (APEC), 2012 Twenty-seventh Annual IEEE, pages: 2279 - 2284, DOI: 10.1109/APEC.2012.6166140 IEEE Conference Publications.

[20] V. Tarateeraseth, "EMI filter design: part II: Measurement of noise sources impedances", Electromagnetic Compatibility Magazine, IEEE, vol. 1, pp.42-49,2012. 